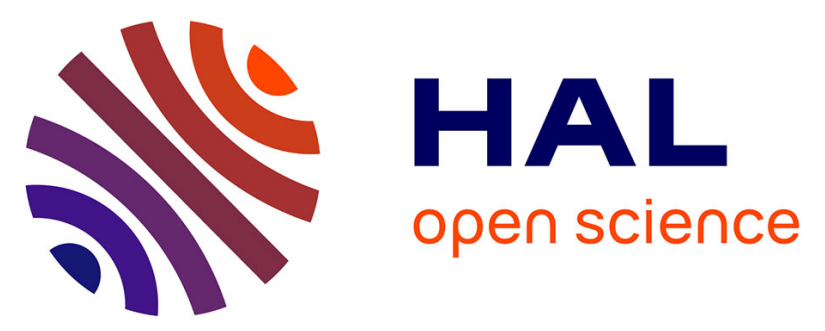

\title{
Endoplasmic reticulum stress and mineralization inhibition mechanism by the resinous monomer HEMA
}

E. Diamanti, S. Mathieu, C. Jeanneau, E. Kitraki, P. Panopoulos, G. Spyrou, I. About

\section{- To cite this version:}

E. Diamanti, S. Mathieu, C. Jeanneau, E. Kitraki, P. Panopoulos, et al.. Endoplasmic reticulum stress and mineralization inhibition mechanism by the resinous monomer HEMA. International Endodontic Journal, 2013, 46 (2), pp.160-168. 10.1111/j.1365-2591.2012.02103.x . hal-03551981

\author{
HAL Id: hal-03551981 \\ https://hal.science/hal-03551981
}

Submitted on 2 Feb 2022

HAL is a multi-disciplinary open access archive for the deposit and dissemination of scientific research documents, whether they are published or not. The documents may come from teaching and research institutions in France or abroad, or from public or private research centers.
L'archive ouverte pluridisciplinaire $\mathbf{H A L}$, est destinée au dépôt et à la diffusion de documents scientifiques de niveau recherche, publiés ou non, émanant des établissements d'enseignement et de recherche français ou étrangers, des laboratoires publics ou privés. 


\title{
Endoplasmic reticulum stress and mineralization inhibition mechanism by the resinous monomer HEMA
}

\author{
E. Diamanti ${ }^{1,2}$, S. Mathieu ${ }^{3}$, C. Jeanneau ${ }^{4}$, E. Kitraki ${ }^{1}$, P. Panopoulos ${ }^{1}$, G. Spyrou ${ }^{2} \&$ \\ I. About ${ }^{4}$ \\ ${ }^{1}$ Departments of Endodontics and Basic Sciences, Dental School, University of Athens, Athens, Greece; ${ }^{2}$ Biochemistry Division, \\ Foundation for Biomedical Research, Academy of Athens, Athens, Greece; ${ }^{3}$ INSERM UMR 911, CR02, Aix-Marseille Université, \\ Marseille, France; and ${ }^{4}$ Aix-Marseille Université, CNRS, ISM UMR 7287, 13288, Marseille cedex 09, France
}

\begin{abstract}
Diamanti E, Mathieu S, Jeanneau C, Kitraki E, Panopoulos P, Spyrou G, About I. Endoplasmic reticulum stress and mineralization inhibition mechanism by the resinous monomer HEMA.
\end{abstract}

Aim To investigate the expression of two endoplasmic reticulum (ER)-resident key chaperone proteins, ERdj5 and BiP, under the influence of resinous monomers and its relationship with the inhibition of mineralization caused by the monomer 2-hydroxyethyl methacrylate (HEMA).

Methodology The ERdj5 and BiP expression was studied in vitro, in primary human pulp cell cultures after treatment with three different HEMA concentrations at different time periods. Subsequently, the expression of both the odontoblast markers dentine sialoprotein (DSP) and osteonectin (OSN) was studied in human pulp cells under the same conditions.

Results The ERdj5 and BiP expression was upregulated in the pulp cells. DSP and OSN were largely dispersed in the cytoplasm in control cell cultures but accumulated in a perinuclear area after exposure to HEMA. Their expression levels were not affected.

Conclusions The increased expression of ERdj5 and BiP may reflect activation of ER stress. DSP and OSN accumulation into the cells may lead to their secretion arrest and inhibition of dentine matrix formation. These events may elucidate the mechanism by which HEMA inhibits the mineralization process.

Keywords: BiP, dentine sialoprotein, endoplasmic reticulum stress, ERdj5, HEMA, mineralization, osteonectin, resinousmonomers.

\section{Introduction}

Composite resins and other resinous materials such as dentine adhesives and resin-modified glass-ionomer cements are widely used. Several studies have shown that one major concern in using resinous materials at the dentine or pulp surface is the leaching of uncured

Correspondence: Dr Evangelia Diamanti, Department of Basic Sciences, Section of Basic Sciences and Oral Biology, Dental School, University of Athens, 2 Thivon St, 11527, Goudi, Athens, Greece (e-mail: ediamanti@dent.uoa.gr or kelly.diamanti@gmail.com). monomers and their subsequent effects on pulp cells. Initially, this leaching is because of incomplete polymerization of the material and later on to their degradation (Goldberg 2008). This leads to monomer diffusion into the adjacent aqueous phase and then through dentine to the pulp space (Gerzina et al. 1991, Gerzina \& Hume 1994). The cytotoxicity of resinous monomers has been studied in vitro by numerous investigations and it has been shown that the degree of their cytotoxicity depends on their concentration (Bouillaguet et al. 1996). The remaining dentine thickness is also a critical parameter for the degree of monomer diffusion across dentine (Hume \& Gerzina 1996). 
2-hydroxyethyl methacrylate (HEMA) is a commonly used monomer compound of resin-based restorative materials, and studies have shown leakage of unpolymerized HEMA from restorations, primers and adhesives (Gerzina \& Hume 1996, Geurtsen et al. 1998a, Kaga et al. 2001). HEMA can diffuse rapidly across dentine towards the pulp because of its small molecular weight and high water solubility (Bouillaguet et al. 1996, Hume \& Gerzina 1996). The $\mathrm{ID}_{50}$ of HEMA varies from 0.19 to $12 \mathrm{mmol} \mathrm{L}^{-1}$ depending on the types of assays and cells used (Yoshii 1997, Geurtsen et al. 1998b, Ratanasathien et al. 2007). HEMA in vitro can cause DNA damage, which may lead to cell death by apoptosis (Paranjpe et al. 2005, Samuelsen et al. 2008, Pawlowska et al. 2010). Various signalling mechanisms have been implicated in the apoptotic process including reactive oxygen species (ROS) formation and differential MAP-kinase activation (Spagnuolo et al. 2004, Samuelsen et al. 2007). The depletion of the important antioxidant glutathione and the induction of oxidative stress are proposed as being mainly responsible for the cytotoxic effects of high HEMA concentrations ( $>1 \mathrm{mmol} \mathrm{L}^{-1}$ ) (Chang et al. 2005, Lee et al. 2006).

The effects of rather high monomers concentrations after a short-time exposure that are described in most of the relevant studies may correspond to the initial phase after the application of a resinous material in a cavity. When this cavity is a deep dentinal cavity or the material is applied directly onto the dental pulp during a pulp capping procedure, these observations are amplified (Bouillaguet et al. 1996). In this case, even low monomer concentrations may have a considerable impact. It is also known that residual monomer leakage continues for long periods (Bouillaguet et al. 1996, Gerzina \& Hume 1996). To understand the intracellular action mechanisms of monomers under these conditions, low monomers concentrations have been used in studies in vitro (Bouillaguet et al. 2000, Noda et al. 2002).

It has been shown that when resinous materials are applied in a close proximity or direct contact with the pulp tissue, the monomers can interfere with dentine regeneration. Some authors have supported this procedure (Cox et al. 1996), but most investigations demonstrated a severe inflammation and a complete absence of mineralization even after 2 months (Hebling et al. 1999). During pulp healing, pulp progenitor cells may differentiate into odontoblast-like cells, which subsequently start to secrete the matrix of reparative dentine. The resinous monomers may play a role in the phenomena that lead to odontoblast differentiation indispensable to pulp repair. Indeed, a decrease induced by another common monomer (triethylene glycol dimethacrylate - TEGDMA) in the expression of genes involved in dentine synthesis in vitro was reported recently by investigating marker genes such as collagen I, alkaline phosphatase (ALP), bone sialoprotein, osteocalcin, Runx 2 and dentine sialophosphoprotein (DSPP) (Galler et al. 2011). Moreover, previous work has revealed that the expression of proteins including collagen I, osteonectin (OSN) and dentine sialoprotein (DSP), which are involved in mineralization, decreased after exposure to low concentrations of HEMA (1$10 \mu \mathrm{mol} \mathrm{L}^{-1}$ ) for 4 weeks (About et al. 2002). DSP is a key protein involved in the initiation and regulation of dentine mineralization. It is believed to play a regulatory role in the mineralization of reparative dentine and it serves as a specific marker for odontoblasts (Butler \& Ritchie 1995, Bègue-Kirn et al. 1998, Papagerakis et al. 2002, Wei et al. 2007).

The inhibition of mineralization caused by HEMA led to the hypothesis that the secretion of proteins indispensable for the process of mineralization could be in some way hindered at the intracellular level. This could involve the endoplasmic reticulum (ER) compartment as this is where a tightly regulated quality control system determines the secretory proteins fate. Specifically, the ER is responsible for protein folding and the recognition and selection of the proteins that are potentially cytotoxic and must be translocated to the cytosol for disintegration. When the ER sorting capacity is reached, unfolded or misfolded proteins accumulate in the ER, leading to a situation known as ER stress (Marciniak \& Ron 2006, Anelli \& Sitia 2008). Changes in the cell redox state (oxidative stress), amongst several other stimuli, are a main cause of ER stress. The cell adaptive response to ER stress is an intracellular signalling cascade named Unfolded Protein Response (UPR). The UPR inhibits protein synthesis and induces protein folding and degradation pathways (Ron \& Walter 2007). The increase in the protein folding capacity of the ER is achieved mainly by inducing the expression of ER chaperones. These are proteins endowed with oxidoreductase activity that catalyse the formation, isomerization and reduction in disulphide bonds in proteins that are undergoing folding and quality control. Amongst ER-resident chaperones, ERdj5 is a key chaperone, member of a family with seven proteins, which features a unique combination of domains including a J domain at the N-terminal point, a 
protein disulphide isomerase (PDI)-like domain and six thioredoxin domains with active CXXC motifs. Like other ER-resident proteins (BiP, PDI), ERdj5 also posses the conserved ER retention sequence KDEL at the C-terminal point (Cunnea et al. 2003, Hagiwara et al. 2011). ERdj5 is ubiquitously expressed and particularly abundant in tissues with high secretory activity like pancreas and testis. In the oral cavity, ERdj5 is highly expressed in the epithelium and the sublingual salivary glands (Cunnea et al. 2003). ERdj5 expression is induced under ER stress conditions, upregulated by UPR and can sensitize cells to ER-dependent apoptosis, by abolishing eIF2a phosphorylation through inactivating the PERK kinase (Thomas \& Spyrou 2009). It has been shown that ERdj 5 is connected to the UPR response and is necessary for the ER-associated degradation (ERAD) of misfolded proteins through its physical and functional interaction with EDEM1 (ER degradation-enhancing $\alpha$-mannosidaselike protein) and BiP (Ig heavy-chain-binding protein), an Hsp70 family molecular chaperone (Dong et al. 2008, Ushioda et al. 2008, Ushioda \& Nagata 2011, Hagiwara \& Nagata 2012).

The goal of the present study is to elucidate the mechanism of inhibition of mineralization by the resinous monomer HEMA. It is hypothesized that the inhibition of DSP and OSN secretion by HEMA may be due to a condition of ER stress and activation of the UPR pathway. Therefore, the expression of ERdj5 and BiP, ER-resident key chaperone proteins involved in the UPR, was investigated in vitro under increasing HEMA concentrations at different short-time periods. The intracellular fate of DSP and OSN was also checked under the same conditions.

\section{Materials and methods}

\section{Culture of dental pulp cells}

Normal immature impacted third molars freshly extracted from 16- to 18-year-old patients were used after informed consent was obtained in compliance with the French and Greek legislation. Immediately after extraction, the teeth were swabbed with sterile gauze, cut with a diamond bur in two pieces and then transferred into a culture hood to perform the rest of the procedures under sterile conditions. The dental pulps were removed with forceps and then minced into tiny pieces with scalpels. The explants were cultured in DMEM medium (Lonza, Basel, Switzerland) supplemented with $10 \%$ foetal bovine serum (Gibco, Invitrogen, Life Technologies Co., Carlsbad, CA, USA), $100 \mathrm{UI} \mathrm{mL}^{-1}$ penicillin, $100 \mu \mathrm{g} \mathrm{mL}^{-1}$ streptomycin (Lonza), $0.25 \mu \mathrm{g} \mathrm{mL}^{-1}$ amphotericin B (Fungizone $^{\circledR}$, Gibco, Invitrogen) and $2 \mathrm{mmol} \mathrm{L}^{-1}$ $\beta$-glycerophoshate ( $\beta$-GP) (Sigma Chemical Co., St Louis, MO, USA). The cultures were maintained at $37{ }^{\circ} \mathrm{C}, 5 \% \mathrm{CO}_{2}$ and $95 \%$ air. The culture medium was changed every other day. Confluent cultures were collected by trypsination (trypsin/EDTA, Lonza) and subcultured. All experiments were performed when cells were between 3rd and 5th passage.

\section{HEMA treatment}

To evaluate the effect of HEMA on the expression of ERdj5, BiP, DSP and OSN, the cultured cells were incubated with medium containing HEMA (97\%, Sigma Chemical Co., CAS 868-77-9) at $10 \mu \mathrm{mol} \mathrm{L}^{-1}$, $50 \mu \mathrm{mol} \mathrm{L}{ }^{-1}$ or $100 \mu \mathrm{mol} \mathrm{L}{ }^{-1}$ for $15 \mathrm{~min}$ and $1 \mathrm{~h}$. The incubation with HEMA was carried out after trypsination and subculture of cells cultured with $2 \mathrm{mmol} \mathrm{L}{ }^{-1} \beta$-GP for 2 weeks.

\section{Western blot analysis}

Whole cell lysates were prepared by adding lysis buffer (HEPES $10 \mathrm{mmol} \mathrm{L}^{-1}, \mathrm{NaCl} 200 \mathrm{mmol} \mathrm{L}^{-1}, \mathrm{MgCl}_{2}$ $2.5 \mathrm{mmol} \mathrm{L}^{-1}, \mathrm{CaCl}_{2} 2 \mathrm{mmol} \mathrm{L}{ }^{-1}$, EDTA $5 \mathrm{mmol} \mathrm{L}{ }^{-1}$, Triton X-100 1.5\%). The protein concentration was determined with Bradford reagent (Sigma Aldrich Co., St Louis, MO, USA). Proteins (30 $\mu \mathrm{g}$ per sample) were resolved on polyacrylamide gels (NuPage ${ }^{\circledR}$ Novex 4 $12 \%$ Bis-Tris Gel $1.0 \mathrm{~mm} 10$ wells, Invitrogen), transferred onto nitrocellulose membranes and probed with either the anti-DSP rabbit antibody (Santa Cruz Biotechnology, Inc., Santa Cruz, CA, USA, 1/200), the anti-ERdj5 rabbit antibody (Proteintech Group, Inc., Chicago, IL, USA, 1/500) or the anti-Glyceraldehyde-3Phosphate Dehydrogenase (GAPDH) mouse antibody (Millipore, Billerica, MA, USA, 1/10 000). The incubation was performed overnight at $4{ }^{\circ} \mathrm{C}$ in TBS $1 \mathrm{x}$ supplemented with $0.05 \%$ Tween 20 and 5\% dry nonfat milk. Incubation with the secondary antibodies followed for $2 \mathrm{~h}$ at room temperature (RT). A goat anti-rabbit IgGHRP was used for ERdj5 and DSP (dilution 1/2000) and a goat anti-mouse IgG-HRP for GAPDH (1/2500) (both from Santa Cruz Biotechnology). The proteins were visualized using ECL Western blotting detection reagents (Pierce ECL Western Blotting Substrate, ThermoScientific, Rockford, IL, USA). Each experiment was conducted in triplicate. Quantification of the optical 
density of the protein bands on the films was performed by Image J software (NIH, Bethesda, MD, USA). Normalization of the data was obtained by including a common sample in every electrophoresis. Statistical analysis was carried out with the spss 16.0 software (IBM, Armonk, NY, USA). The results are expressed as mean values of the ratio of the optical density of ERdj 5 or DSP to control GAPDH. One-way ANOvA was used to check the statistical significant differences followed by Tukey test for post hoc analysis. Values of $P<0.05$ were considered as significant.

\section{Immunofluorescence}

Primary pulp cells were cultured in 8-well cell chambers (BD Biosciences, Franklin Lakes, NJ, USA) at 30000 cells $\mathrm{cm}^{-2}$. When $90 \%$ confluency was reached, cells were treated with the medium containing HEMA at concentrations of $10 \mu \mathrm{mol} \mathrm{L}{ }^{-1}$, $50 \mu \mathrm{mol} \mathrm{L}{ }^{-1}$ or $100 \mu \mathrm{mol}$ $\mathrm{L}^{-1}$ for $15 \mathrm{~min}$ and $1 \mathrm{~h}$. After treatment, cells were fixed in $70 \%$ ethanol and kept at $4{ }^{\circ} \mathrm{C}$ at least for $1 \mathrm{~h}$ before analysis. After washing with PBS, cells in the chambers were incubated in PBS containing 0.5\% BSA for $45 \mathrm{~min}$ at RT and incubated overnight at $4{ }^{\circ} \mathrm{C}$ with one of the following antibodies: anti-ERdj5 (rabbit polyclonal, Proteintech, 1/200), anti-DSP (mouse monoclonal, Santa Cruz, 1/200), anti-BiP (rabbit polyclonal, Acris Antibodies, Inc., San Diego, CA, USA, 1/200) and anti-OSN (mouse monoclonal, Takara Bio Inc., Otsu, Shiga, Japan, $5 \mu \mathrm{g} \mathrm{mL}^{-1}$ ), all of them diluted in PBS containing $0.1 \%$ BSA. After washing with PBS and incubation for $45 \mathrm{~min}$ with the fluorescent secondary antibodies (goat anti-rabbit IgG FITC 1/500 and goat anti-mouse IgG TRITC 1/800, all from Jackson ImmunoResearch Europe Ltd, Newmarket, UK) at RT, cells were also incubated with DAPI (Invitrogen, 1/2000) for nuclear counterstaining. After mounting with Glycergel (Dako Corporation, Glostrup, Denmark), the slides were kept at $4{ }^{\circ} \mathrm{C}$ and visualized with fluorescence (Leica DM IRE2, Leica Microsystems, Wetzlar, Germany) or confocal (Leica SP5, Leica Microsystems) microscope.

\section{Results}

In vitro effect of HEMA monomer on the expression and localization of ERdj 5 and BiP chaperones in dental pulp cells

Human pulp cells were observed under phase contrast microscopy under normal conditions (Fig. 1a) and after $1 \mathrm{~h}$ treatment with $50 \mu \mathrm{mol} \mathrm{L}{ }^{-1}$ HEMA (Fig. 1b). Cells had a fibroblast appearance and incubation with HEMA did not alter their morphology. Under normal control culture conditions, ERdj5 immunostaining, in green, was characteristically located into the ER with a wide granular distribution in the cytoplasm (Fig. 1c). One hour after incubation with $100 \mu \mathrm{mol} \mathrm{L}{ }^{-1}$ HEMA, the distribution of ERdj5 was the same, however, an obvious increase was observed in its expression, which was seen in the form of accumulations (Fig. 1d). This expression pattern was common for all HEMA concentrations used $\left(10,50,100 \mu \mathrm{mol} \mathrm{L} \mathrm{L}^{-1}\right)$. BiP showed also a wide granular expression into the cytoplasm (Fig. 1e), which was increased after HEMA treatment (Fig. 1f), corresponding to accumulations into the ER, similar to ERdj5.

To quantify the effect of HEMA on ERdj5 expression, a western blot analysis of whole cell lysates was carried out. An increase in ERdj 5 expression can be observed after $15 \mathrm{~min}$ and $1 \mathrm{~h}$ of incubation with HEMA (Fig. 2a). Statistical analysis on three independent experiments (Fig. 2b) revealed that this increase in ERdj 5 expression was significant after $15 \mathrm{~min}$ of treatment only for the higher concentrations (50) and $100 \mu \mathrm{mol} \mathrm{L}{ }^{-1}$ ) and after $1 \mathrm{~h}$ for all concentrations. For 10 and $50 \mu \mathrm{mol} \mathrm{L}{ }^{-1}$, the increase in the expression was proportional to the length of the treatment, but for $100 \mu \mathrm{mol} \mathrm{L}{ }^{-1}$, the maximum of the expression was reached only after 15 min that then decreased after $1 \mathrm{~h}$ even if the difference was not significant.

\section{In vitro effect of HEMA monomer on the expression and localization of DSP and OSN in dental pulp cells}

Immunofluorescence was used to investigate the localization of DSP and OSN into the cells before and after HEMA treatment. Under normal culture conditions, DSP and OSN expression were located in the cytoplasm (Fig. 3a,c respectively). One hour after incubation with HEMA, there was an obvious shift of DSP and OSN expression into a perinuclear area (Fig. 3b,d respectively). The effect was more evident at the highest HEMA concentration $\left(100 \mu \mathrm{mol} \mathrm{L}{ }^{-1}\right)$. To quantify the effect of HEMA on DSP expression, a western blot analysis of whole cell lysates was carried out. No difference was observed in DSP levels even after $1 \mathrm{~h}$ of treatment with different HEMA concentrations (data not shown).

To investigate in detail the translocation of DSP after HEMA treatment, colocalization of ERdj5 and DSP expression was investigated with confocal 

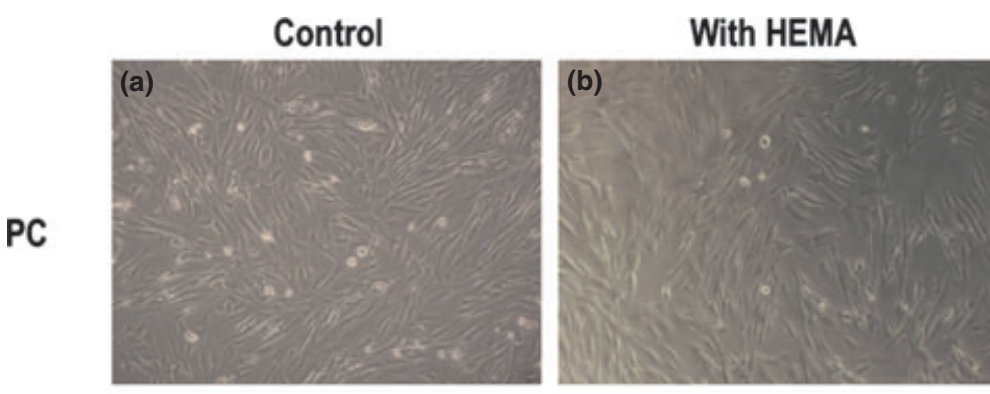

Figure 1 Fluorescent microscopic
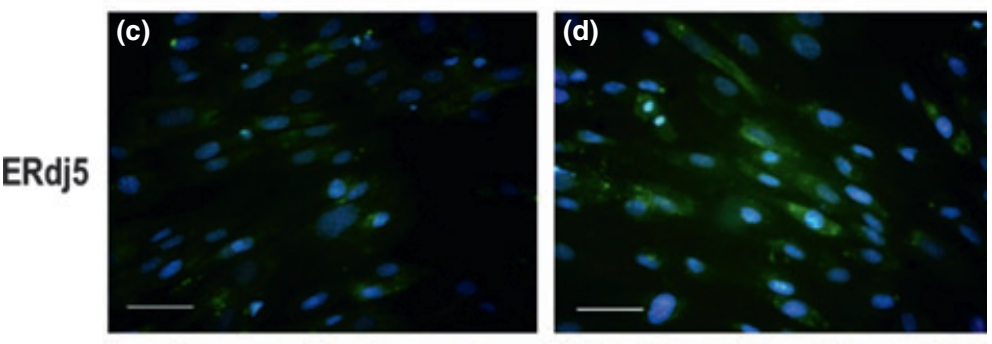
analysis of HEMA effect on ERdj5 and BiP expression. Phase contrast (PC) images of pulp cells under normal conditions (a) or after treatment with HEMA $50 \mu \mathrm{mol} \mathrm{L}{ }^{-1}$ for $1 \mathrm{~h}$ (b). ERdj5 (c) and BiP (e) expression, in green, under normal pulp culture conditions are covering a large area of the cytoplasm, which can be identified as the ER. One hour after incubation with $100 \mu \mathrm{mol} \mathrm{L}{ }^{-1}$ HEMA, the expression of both proteins are increased ( $\mathrm{d}$ and $\mathrm{f}$, respectively). Blue colour is DAPI staining in the nuclei. Scale bar $=50 \mu \mathrm{m}$.
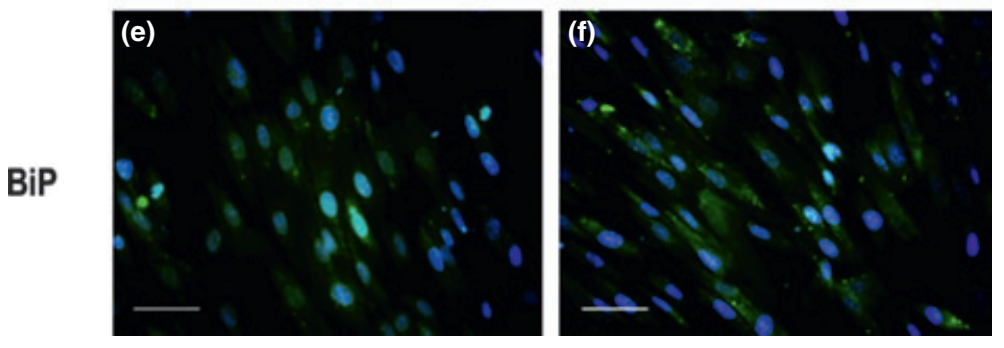

microscopy. Figure 4 a shows that under normal culture conditions, ERdj5 (in green) is localized into the ER, exhibiting a granular cytoplasmic expression, which is significantly increased after HEMA treatment (Fig. 4b). DSP (in red) under normal conditions has a punctiform cytoplasmic expression (Fig. 4a) whilst, after HEMA treatment (Fig. 4b), it is translocated to a perinuclear compartment.

\section{Discussion}

In this study, it was demonstrated that the inhibition of mineralization by HEMA may be related to the intracellular accumulation of DSP and OSN and the subsequent inhibition of their secretion. The increase in the expression of ERdj 5 very quickly after the incubation of primary pulp cells with HEMA indicates the possible activation of ER stress mechanisms.

2-hydroxyethyl methacrylate has been shown to interfere with several cellular processes. This monomer together with other monomers (mainly TEGDMA) has been directly implicated in vitro in the induction of oxidative stress in cells via the production of ROS, causing damage to DNA, proteins and lipids, which lead to biological effects ranging from changes in signal transduction pathways and gene expression levels to cellular transformation and mutagenesis (Stanislawski et al. 2003, Lefeuvre et al. 2005, Nocca et al. 2010, Krifka et al. 2011). Consequently, the presence of these monomers even at low concentrations has several effects on cell survival, proliferation and apoptosis (Spagnuolo et al. 2006, 2008, Schweikl et al. 2008, Krifka et al. 2010).

The physiological process of pulp wound healing, which includes the differentiation of pulp cells into odontoblast-like cells and the secretion and deposition of tertiary dentine, is also affected by the presence of monomers. A recent study has shown that TEGDMA leads to downregulation of genes coding for proteins participating in the mineralization process (Galler et al. 2011). Previous work has shown that the incubation of primary pulp cells with low HEMA concentrations $\left(1-10 \mu \mathrm{mol} \mathrm{L}{ }^{-1}\right)$ led to a reduced expression and a decrease in the secretion of DSP, OSN and collagen type I in the extracellular matrix and to a complete inhibition of mineralization after a 4-week 


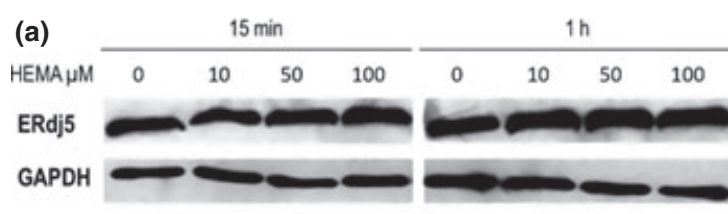

(b)

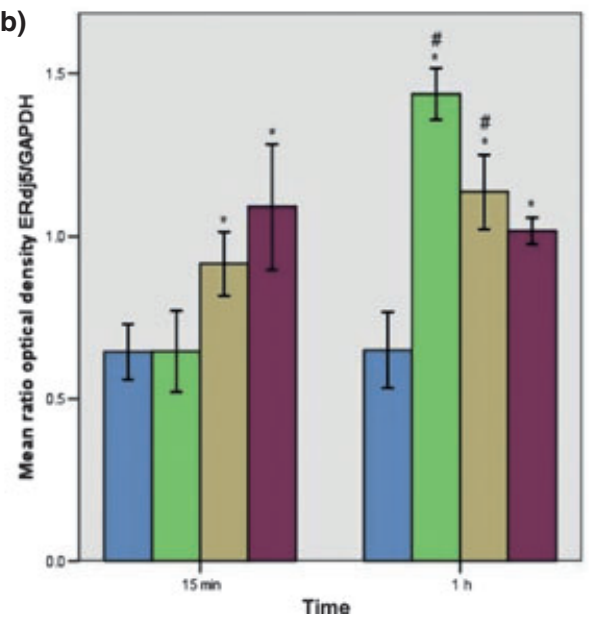

Figure 2 Quantification of HEMA effect on ERdj5 expression. Western blots (a) show the expression of ERdj5 $15 \mathrm{~min}$ and $1 \mathrm{~h}$ after exposure of primary human pulp cells to different HEMA concentrations. GAPDH was used as a control (housekeeping gene). In histogram (b), results are presented as the mean ratio of the optical density of ERdj5 bands to $\mathrm{GAPDH} \pm \mathrm{SE}$. *Denotes statistical significant differences between different HEMA concentrations at each time point, whilst \# denotes statistical significant differences at each HEMA concentration between the different time points.

incubation period with $\beta$-GP (About et al. 2002). DSP and OSN are proteins that characterize a mature odontoblast, participating in one of its major functions, the mineralization of the organic matrix of dentine. The choice to study these proteins instead of others was based on their specificity and importance. In the present study, it was demonstrated that the incubation of primary human pulp cells with low HEMA concentrations $\left(10, \quad 50,100 \mu \mathrm{mol} \mathrm{L}^{-1}\right)$ resulted in the accumulation of DSP and OSN in a perinuclear compartment. When HEMA was directly applied in a primary pulp cell culture, an increase was seen in the expression of ERdj5 and BiP, two ER chaperones involved in ER stress, $1 \mathrm{~h}$ after HEMA treatment even at the lowest concentration of $10 \mu \mathrm{mol} \mathrm{L}{ }^{-1}$, which could be even lower at the intracellular level, as shown recently (Nocca et al. 2010). This may indicate the induction of an ER stress response. After the incubation of pulp cells with HEMA, a shift was also seen in the expression of DSP and OSN from the cytoplasm to a perinuclear area (ER). These observations indicate the possible retainment of DSP and OSN into the cell because of the general suspension of protein folding and processing caused by the UPR response. In this case, DSP and OSN may not be able to exert their physiological function and the formation of the dentine matrix is blocked. This may lead to the absence of any mineralization, as was observed after the continuous incubation with HEMA for 4 weeks (About et al. 2002). A continuous ER stress response and the induction of UPR may explain these observations. Incubation of cells with HEMA for shorter time periods as in the present study may lead to a more transient effect. It was interesting to notice that the increase in ERdj5 expression was already evident 15 min after incubation with the highest HEMA concentration $\left(100 \mu \mathrm{mol} \mathrm{L}{ }^{-1}\right)$, whilst it started to decrease $1 \mathrm{~h}$ after incubation with the same monomer concentration. This may imply a quicker onset of the ER stress response, which afterwards begins to reverse, probably as a result of a successful activation of UPR. A similar response should be expected for the lower HEMA concentrations with a slight time shift.

It is known that under a cavity with a resinous filling, pulp cells activity is upregulated and they start to secrete the extracellular matrix of tertiary dentine (Ferracane et al. 2010). At this point of their life, these cells are becoming very secretive and therefore probably prone to the appearance of ER stress, which by definition is induced by a heavy duty of protein synthesis and secretion. It is possible that under these conditions, ER stress may appear as a periodical transient phenomenon elicited by the continuous leach of resinous monomers. The extent of the insult, though, could permit finally the restoration of the ER homoeostasis and the normal proceeding of tertiary dentinogenesis.

Endoplasmic reticulum stress has gained a great interest lately because of its speculated correlation with very important events such as cell life cycle and fate. It is a complicated phenomenon with many pathways involved each of which may interfere with several cellular processes. The induction of ER stress by HEMA may be related to the fundamental role of oxidative stress in its action mechanism. Recent evidence suggests the existence of a close interrelationship between ER stress and oxidative stress. Protein folding and generation of ROS as a byproduct of protein oxidation in the ER are closely linked events, whilst activation of UPR occurs also as a response to oxidative stress as an adaptive mechanism 


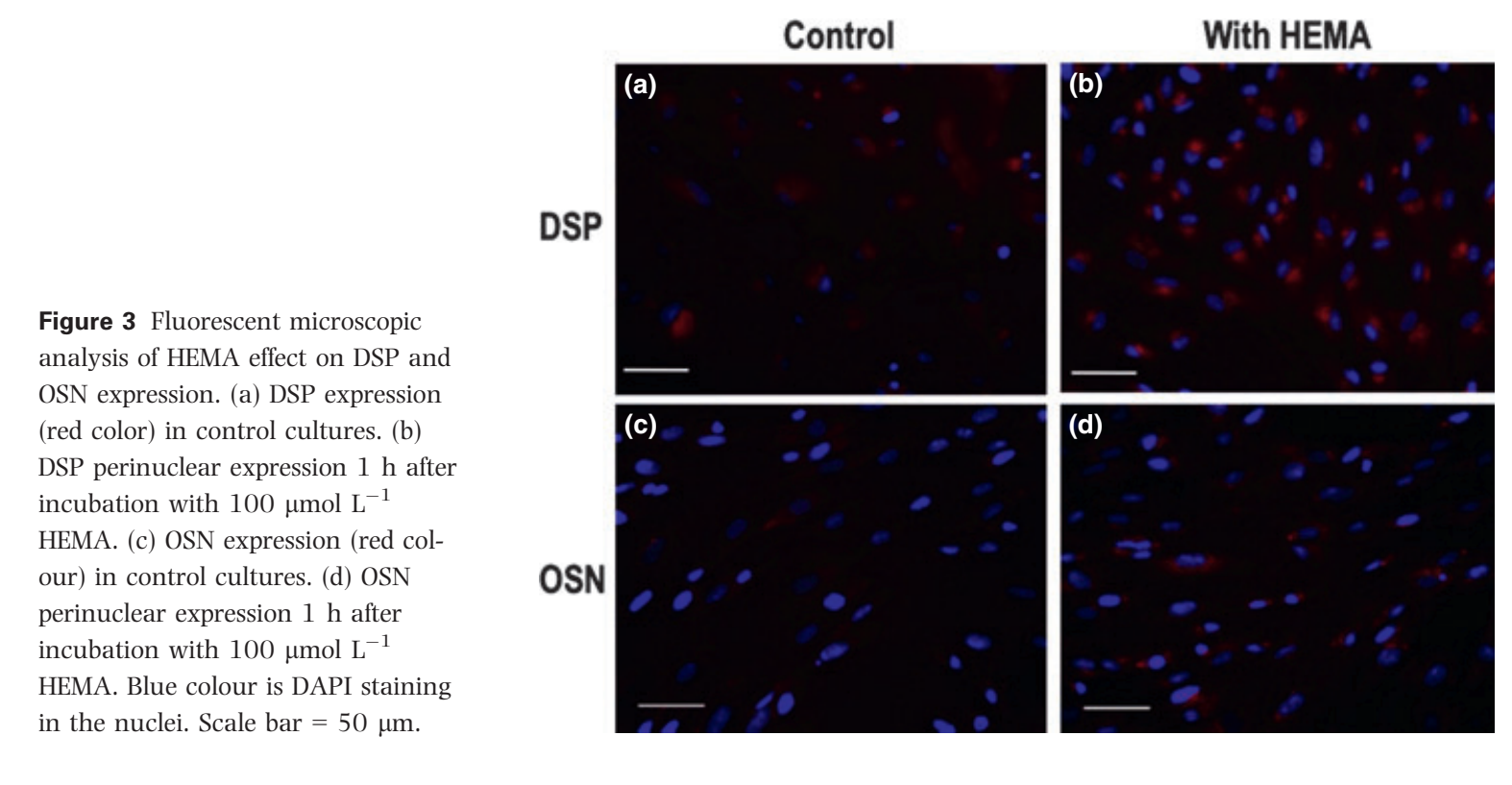

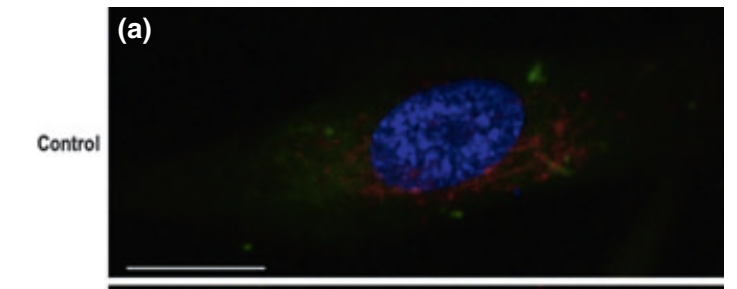

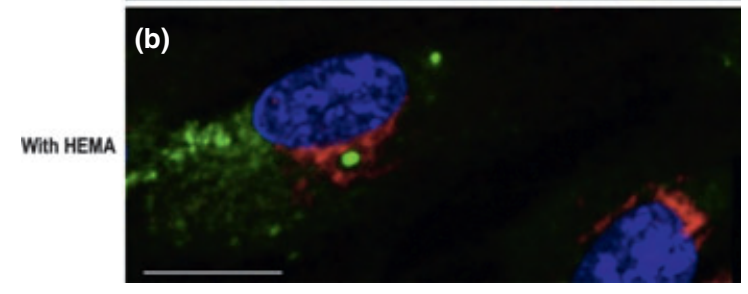

Figure 4 Confocal microscopic analysis of HEMA effect on DSP and ERdj5 localization. Merged confocal fluorescent images showing the intracellular distribution of DSP (red) and ERdj5 (green) under normal cell culture conditions (a) and after $1 \mathrm{~h}$ of incubation with $100 \mu \mathrm{mol} \mathrm{L}^{-1}$ HEMA (b). Scale bar $=25 \mu \mathrm{m}$.

to preserve cell function and survival (Malhotra \& Kaufman 2007). However, to elucidate the exact role of the ER stress under the influence of resinous monomers, further research is required. This should include other proteins that are known to participate in ER stress mechanisms such as proteins related to the ER stress-related (UPR) signalling cascades (PERK, IRE1a, ATF6). Especially the axis PERK/eIF2 $\alpha /$ ATF4 could be of special interest as the ATF4 (activating transcription factor 4) may be involved in osteoblast differentiation and bone formation (Franceschi et al. 2009, Saito et al. 2009).

\section{Conclusions}

Controversy exists concerning the safety of direct pulp capping with resin materials. A serious concern arises because of the inhibition of mineralization provoked by the resinous monomers. This study shows that this may be related to an entrapment of DSP and OSN into the cell. This prevents the proteins from participating in the physiological process of dentine regeneration. The results also provide evidence that an aspect of HEMA cytotoxicity may be related to the induction of ER stress in the pulp cells. Understanding the mechanism by which monomers leaching from resinous materials interfere with the regeneration of the pulp-dentine complex can help develop new methods for contemporary dental treatment which will incorporate ways of avoiding the adverse effects of the existing resinous materials.

\section{Acknowledgements}

This study is part of the $03 \mathrm{ED} / 357$ research project, implemented within the framework of the 'Reinforcement Programme of Human Research Manpower' (PENED) and cofinanced by National and Community Funds (25\% from the Greek Ministry of DevelopmentGeneral Secretariat of Research and Technology and 
75\% from E.U.-European Social Fund) and supported by institutional funding from the French 'Ministère de l'éducation nationale, de l' enseignement supérieur et de la recherche'.

\section{Conflict of interest}

The authors declare that they have no conflict of interest.

\section{References}

About I, Camps J, Mitsiadis T, Bottero MJ, Butler W, Franquin JC (2002) Influence of resinous monomers on the differentiation in vitro of human pulp cells into odontoblasts. Journal of Biomedical Materials Research (Applied Biomaterials) 63, 418-23.

Anelli T, Sitia R (2008) Protein quality control in the early secretory pathway. European Molecular Biology Organization Journal 27, 315-27.

Bègue-Kirn C, Krehsbach PH, Bartlett JD, Butler WT (1998) Dentin sialoprotein, dentin phosphoprotein, enamelysin and ameloblastin: tooth-specific molecules that are distinctively expressed during murine dental differentiation. European Journal of Oral Sciences 106, 963-70.

Bouillaguet S, Wataha JC, Hanks CT, Ciucchi B, Holz J (1996) In vitro cytotoxicity and dentin permeability of HEMA. Journal of Endodontics 22, 244-8.

Bouillaguet S, Wataha JC, Virgillito M, Gonzalez L, Rakish DR, Meyer JM (2000) Effect of sub-lethal concentrations of HEMA (2-hydroxyethyl methacrylate) on THP-1 human monocyte-macrophages, in vitro. Dental Materials 16, 213 -7 .

Butler WT, Ritchie H (1995) The nature and functional significance of dentin extracellular matrix proteins. International Journal of Developmental Biology 39, 169-79.

Chang HH, Guo MK, Kasten F et al. (2005) Stimulation of glutathione depletion, ROS production and cell cycle arrest of dental pulp cells and gingival epithelial cells by HEMA. Biomaterials 26, 745-53.

Cox CF, Sübay RK, Suzuki S, Suzuki SH, Ostro E (1996) Biocompatibility of various dental materials: pulp healing with a surface seal. International Journal of Periodontics and Restorative Dentistry 16, 240-51.

Cunnea PM, Miranda-Vizuete A, Bertolis G et al. (2003) ERdj5, an endoplasmic-reticulum (ER)-resident protein containing DnaJ and thioredoxin domains, is expressed in secretory cells or following ER stress. Journal of Biological Chemistry 278, 1059-66.

Dong M, Bridges JP, Apsley K, Xu Y, Weaver TE (2008) ERdj4 and ERdj5 are required for endoplasmic reticulum-associated protein degradation of misfolded surfactant protein C. Molecular Biology of the Cell 19, 2610-30.
Ferracane JL, Cooper PR, Smith AJ (2010) Can interaction of materials with the dentin-pulp complex contribute to dentin regeneration? Odontology 98, 2-14.

Franceschi RT, Ge C, Roca H, Jiang D (2009) Transcriptional regulation of osteoblasts. Cells Tissues Organs 189, 144-52.

Galler KM, Schweikl H, Hiller K-A et al. (2011) TEGDMA reduces mineralization in dental pulp cells. Journal of Dental Research 90, 257-62.

Gerzina TM, Hume WR (1994) The effect of dentine on the release of TEGDMA from resin composite in vitro. Journal of Oral Rehabilitation 21, 463-8.

Gerzina TM, Hume WR (1996) Diffusion of monomers from bonding resin-resin composite combinations through dentine in vitro. Journal of Dentistry 24, 125-8.

Gerzina TM, Picker K, Hood A, Hume W (1991) Toxicity and quantitative analysis of TEGDMA and composite resin eluates. Journal of Dental Research 70, 424.

Geurtsen W, Spahl W, Leyhausen G (1998a) Residual monomer/additive release and variability in cytotoxicity of lightcuring glass-ionomer cements and compomers. Journal of Dental Research 77, 2012-9.

Geurtsen W, Lehmann F, Spahl W, Leyhausen G (1998b) Cytotoxicity of 35 dental resin composite monomers/additives in permanent 3T3 and three human primary fibroblast cultures. Journal of Biomedical Materials Research 41, 474-80.

Goldberg M (2008) In vitro and in vivo studies on the toxicity of dental resin components: a review. Clinical Oral Investigations 12, 1-8.

Hagiwara M, Nagata K (2012) Redox-dependent protein quality control in the endoplasmic reticulum: folding to degradation. Antioxidants \& Redox Signaling 16, 1119-28.

Hagiwara M, Maegawa K, Suzuki M et al. (2011) Structural basis of an ERAD pathway mediated by the ER-resident protein disulfide reductase ERdj5. Molecular Cell 41, 432-44.

Hebling J, Giro EM, Costa CA (1999) Biocompatibility of an adhesive system applied to exposed human dental pulp. Journal of Endodontics 25, 676-82.

Hume WR, Gerzina TM (1996) Bioavailability of components of resin-based materials which are applied to teeth. Critical Reviews in Oral Biology \& Medicine 7, 172-9.

Kaga M, Noda M, Ferracane JL, Nakamura W, Oguchi H, Sano H (2001) The in vitro cytotoxicity of eluates from dentin bonging resins and their effect on tyrosine phosphorylation of L929 cells. Dental Materials 17, 3339.

Krifka S, Petzel C, Hiller KA et al. (2010) Resin monomerinduced differential activation of MAP kinases and apoptosis in mouse macrophages and human pulp cells. Biomaterials 31, 2964-75.

Krifka S, Seidenader C, Hiller K-A, Schmaltz G, Schweikl H (2011) Oxidative stress and cytotoxicity generated by dental composites in human pulp cells. Clinical Oral Investigations 16, 215-24. 
Lee DH, Lim BS, Lee YK, Ahn SJ, Yang HC (2006) Involvement of oxidative stress in mutagenicity and apoptosis caused by dental resin monomers in cell cultures. Dental Materials 22, 1086-92.

Lefeuvre M, Amjaad W, Goldberg M, Stanislawski L (2005) TEGDMA induces mitochondrial damage and oxidative stress in human gingival fibroblasts. Biomaterials 26, 5130-7.

Malhotra JD, Kaufman RJ (2007) Endoplasmic reticulum stress and oxidative stress: a vicious cycle or a doubleedged sword? Antioxidants \& Redox Signaling 9, 2277-93.

Marciniak CJ, Ron D (2006) Endoplasmic reticulum stress signaling in disease. Physiological Reviews 86, 1133-49.

Nocca G, D’Antò V, Desiderio C et al. (2010) N-acetylcysteine directed detoxification of 2-hydroxyethyl methacrylate by adduct formation. Biomaterials 31, 2508-16.

Noda M, Wataha JC, Lockwood PE, Volkmann KR, Kaga M, Sano H (2002) Low-dose, long-term exposures to dental material components alter human monocyte metabolism. Journal of Biomedical Materials Research 62, 237-43.

Papagerakis P, Berdal A, Mesbah M et al. (2002) Investigation of osteocalcin, osteonectin and dentin sialophosphoprotein in developing human teeth. Bone 30, 377-85.

Paranjpe A, Bordador LCF, Wang MY, Hume WR, Jewett A (2005) Resin monomer 2-hydroxyethyl methacrylate (HEMA) is a potent inducer of apoptotic cell death in human and mouse cells. Journal of Dental Research 84, $172-7$.

Pawlowska E, Poplawski T, Ksiazek D, Szczepanska J, Blasiak J (2010) Genotoxicity and cytotoxicity of 2-hydroxyethyl methacrylate. Mutation Research 2, 122-9.

Ratanasathien S, Wataha JC, Hanks CT, Dennison JB (2007) Cytotoxic interactive effects of dentin bonding components on mouse fibroblasts. Journal of Dental Research 74, 1602-6.

Ron D, Walter P (2007) Signal integration in the endoplasmic reticulum unfolded protein response. Nature Reviews. Molecular Cell Biology 8, 519-29.

Saito A, Ochiai K, Kondo S et al. (2009) Endoplasmic reticulum stress response mediated by the PERK-elF2(alpha)ATF4 pathway is involved in osteoblast differentiation induced by BMP2. Journal of Biological Chemistry 286, 4809-18.

Samuelsen JT, Dahl JE, Karlsson S, Morisbak E, Becher R (2007) Apoptosis induced by the monomers HEMA and
TEGDMA involved formation of ROS and differential activation of the MAP-kinases p38, JNK and ERK. Dental Materials 23, 34-9.

Samuelsen JT, Holme JA, Becher R, Karlsson S, Morisbak E, Dahl JE (2008) HEMA reduces cell proliferation and induces apoptosis in vitro. Dental Materials 24, 134-40.

Schweikl H, Hiller KA, Eckhardt A et al. (2008) Differential gene expression involved in oxidative stress response caused by triethylene glycol dimethacrylate. Biomaterials 29, 1377-87.

Spagnuolo G, Mauro C, Leonardi A et al. (2004) NF-кB protection against apoptosis induced by HEMA. Journal of Dental Research 83, 837-42.

Spagnuolo G, D'Antò V, Cosentino C, Schmalz G, Schweikl H, Rengo S (2006) Effect of N-acetyl-L-cysteine on ROS production and cell death caused by HEMA in human primary gingival fibroblasts. Biomaterials 27, 1803-9.

Spagnuolo G, D'Antò V, Valletta R et al. (2008) Effect of 2hydroxyethyl methacrylate on human pulp cell survival pathways ERK and AKT. Journal of Endodontics 34, 684-8.

Stanislawski L, Lefeuvre M, Bourd K, Soheili-Majd E, Golberg M, Périanin A (2003) TEGDMA-induced toxicity in human fibroblasts is associated with early and drastic glutathione depletion with subsequent production of oxygen reactive species. Journal of Biomedical Materials Research 66A, 476-82.

Thomas CG, Spyrou G (2009) ERdj5 sensitizes neuroblastoma cells to endoplasmic-reticulum stress-induced apoptosis. Journal of Biological Chemistry 284, 6282-90.

Ushioda R, Nagata K (2011) The endoplasmic reticulumassociated degradation and disulfide reductase ERdj5. Methods in Enzymology 490, 235-58.

Ushioda R, Hoseki J, Araki K, Jansen G, Thomas DY, Nagata $\mathrm{K}$ (2008) ERdj5 is required as a disulfide reductase for degradation of misfolded proteins in the ER. Science $\mathbf{3 2 1}$, 569-72.

Wei X, Ling J, Wu L, Liu L, Xiao Y (2007) Expression of mineralization markers in dental pulp cells. Journal of Endodontics 33, 703-8.

Yoshii E (1997) Cytotoxic effects of acrylates and methacrylates: relationships of monomer structures and cytotoxicity. Journal of Biomedical Materials Research 37, 517-24. 